DOI: $10.17957 / \mathrm{IJAB} / 15.1793$

http://www.fspublishers.org

\title{
Salinity Stress Alerts Genome Stability and Genotoxicity of Ocimum basilicum Cultivars
}

\author{
Saqer S. Alotaibi" \\ Department of Biotechnology, College of Science, Taif University, P.O. Box 11099, Taif 21944, Saudi Arabia \\ *For correspondence: Saqer@tu.edu.sa \\ Received 01 February 2021; Accepted 23 March 2021; Published 10 May 2021
}

\begin{abstract}
Salinity is an important abiotic stress that greatly influences growth, secondary product content and genotoxicity in plants. Ocimum basilicum L. (family Lamiaceae) produces a volatile oil, which is used in many pharmaceutical industries, but the oil biosynthesis is affected by salt stress. The aim of this study was to evaluate the effect of salinity stress on genome stability and genotoxicity of three basil cultivars (Gigante, Gralissimum and Verde) using comet assays to study the genotoxic impact of salinity stress $(0,50,100$ and $200 \mathrm{mM} \mathrm{NaCl})$ and a semi-quantitative real time polymerase chain reaction to study terpene gene expression. Both analyses revealed considerable genetic effects of salinity stress on the $O$. basilicum genome, detected by a regular increase in DNA damage and by diversity in the transcript levels of terpene biosynthesis and inhibitor genes. Our findings confirmed that basil plants were affected by $\mathrm{NaCl}$ salinity stress and that exposure to $200 \mathrm{mM} \mathrm{NaCl}$ resulted in significant DNA damage in the form of tail moment, DNA tail percentage and tail length. The accumulation of linalool synthase enzyme (LS) and hexokinase synthase (HK) gene transcripts was greatly increased in response to salinity, whereas FPPS, GPPS and DXR gene transcription was suppressed in all three basil cultivars. (C) 2021 Friends Science Publishers
\end{abstract}

Keywords: Ocimum basilicum; Salt stress; Genotoxicity; Basil cultivars; Genome

\section{Introduction}

Salinity is an environmental stress that affects plant genome persistence, as well as causing substantial damage to crop production, with significant economic and environmental impact in the affected areas. Globally, the effects of soil salinity on the agricultural sector productivity are greater than those of other factors, as increasing soil salinity ratios are converting reclaimed land into acreages unsuitable for cultivation (Saira et al. 2014). Salinity is one of the most important abiotic stresses that affect plant DNA, and plant genotoxicity induced by numerous stress agents is now under intensive investigation by many researchers. The comet assay is now recognised as a promising method for measuring the DNA damage and repair capacity at the single-cell level (Tomas et al. 2000). The accuracy, simplicity and need for only a single cell to obtain reliable results had led to an increased use of the comet assay in plant research that now extends beyond model plants like Arabidopsis thaliana, Allium cepa, Vicia faba or Nicotiana tabacum to a broad range of important crop species (Gichner et al. 2009; Ventura et al. 2013). Previous studies have employed comet assays for the evaluation of genotoxicity caused by chemicals, radiation, phytochemicals, pesticides, contaminated complex matrices, heavy metals and nanoparticles (Ghosh et al. 2015).

Medicinal and aromatic plants have many health benefits, which are found in many important plant families. One of the best known families is the Lamiaceae, as almost all members of this family possess volatile oil trichomes with high terpene contents. In this family, basil is a globally popular member that is widely used for many purposes, including insomnia treatments, pharmaceuticals, flavouring, aromatherapy, cosmetics and perfumes (Sonwa 2000; Labra et al. 2004). Basil is an annual herb, with a height between 20 to $60 \mathrm{~cm}$ and pink and white flowers. The plant is widely cultivated in the Mediterranean basin, Asia, Europe and in many other countries of the world (Omidbaig 2005). Recent studies have explored the importance of essential oils from basil as drug components for leukemia treatments and antibacterial and antifungal products (Moteki et al. 2002). However, the effects of salinity on essential oil production in basil have not been sufficiently investigated.

In the Kingdom of Saudi Arabia (KSA), some areas use saline water for irrigation. In addition, many reclaimed land areas are developing acute soil salinity problems. These factors have encouraged the introduction of new cultivars that are tolerant of soil salinity. Basil plants are economically important in the KSA and worldwide due to their large quantities of several essential oil components, 
including terpenoids and phenylpropane derivatives, which have been characterised as the basic volatile components in basil oil (Hassanpouraghdam et al. 2010). Terpenoids are one of the most diverse classes of plant secondary metabolites, and they participate in many biological processes, including growth, development, photosynthesis and respiration (Gershenzon and Kreis 1999; Rodriguez and Boronat 2002).

Terpenoids also accumulate in plants exposed to environmental stresses, including salinity. Tissue culture technique has been frequently used as a tool to identify the cellular mechanisms that impart salt tolerance and to select for NaCl-tolerant plants. Plant tissue culture also avoids the need to cultivate whole plants, and the growth conditions are easily controlled in plant cell cultures (Davenport et al. 2003; Gu et al. 2004). The use of tissue cultures also simplifies genome analysis, such as by comet assays, for investigation of terpene biosynthesis at the transcriptional level and its behaviour under salinity stress (Ashour et al. 2010). For example, analysis of expression of the linalool synthase enzyme (LS) has confirmed that the accumulation of linalool in Lavendula angustifolia correlates closely with the transcript levels of LS gene (Lane et al. 2010). Several enzymes, including hexokinase synthase (HK), a glycolytic enzyme responsible for the ATP-dependent conversion of hexoses to hexose 6-phosphates (Jyan et al. 1997), and 1deoxy-D-xylulose-5-phosphate synthase (DXS), a principal enzyme of the methylerythritol phosphate pathway, are known to be primarily regulated at the transcription level (Kai et al. 2011).

A number of genes have known involvement in essential oil synthesis. One example is the gene coding for farnesyl diphosphate synthase (FPPS), an important enzyme in the isoprenoid biosynthesis reaction that supplies sesquiterpene precursors for the synthesis of numerous essential metabolites, including ubiquinones, dolichols, sterols and carotenoids, as well as providing substrates for geranyl geranylation and farnesylation of proteins (Szkopińska and Plochocka 2005). Another is the geranyl diphosphate synthase (GPPS) gene that codes for a key enzyme in monoterpene biosynthesis and has a plastid localisation (Tholl et al. 2004). The aim of the present study was to use comet assays to evaluate the transcriptional level of terpene-related genes in tissue cultures of three basil cultivars following exposure to various levels of salinity. The other aim was to review the latest data on the use of this technique as an ideal approach for investigating the genotoxic effects of salinity stress on essential oil production in basil (Ocimum basilicum L.) plants.

\section{Materials and Methods}

The current study was carried out in the Plant Tissue Culture and Molecular Biology Laboratory, Biotechnology department, College of Science, Taif University, Taif, Saudi Arabia, from May 2019 to January 2020.

\section{Plant materials and in vitro salinity assay}

Seeds of three basil cultivars (Ocimum basilicum L. cvs. Gigante, Gralissimum and Verde) were purchased from Alhomaide Company, Taif, Saudi Arabia, and sterilised by washing for $30 \mathrm{sec}$ with $70 \%$ ethanol containing a few drops of Tween20, washing three times with sterilized distilled water and then immersing in 5\% commercial Clorox solution (1\% sodium hypochlorite) for $5 \mathrm{~min}$ in a laminar air flow hood, followed by five washes with sterile distilled water. The sterilized seeds were inoculated aseptically into jars (3 seeds per jar) containing MS nutrient medium (Murashige and Skoog 1962) supplemented with 3\% sucrose and solidified with $(0.7 \%)$ agar. (Prior to inoculation, the $\mathrm{pH}$ was adjusted to 5.8 , and $30 \mathrm{~mL}$ of medium was placed into each culture tube and sterilised by autoclaving at $121^{\circ} \mathrm{C}$ for 20 mins) The seed cultures were maintained in the dark at $25 \pm 2^{\circ} \mathrm{C}$ for 10 days. After germination, the seedlings were transferred to continuous cool white fluorescent light with a $16 \mathrm{~h}$ photoperiod at 2,000-Lux intensity. The germinated explants were then sub-cultured for 14 days under aseptic conditions in the basal MS nutrient medium with added $3 \%$ sucrose, $0.7 \%$ agar, and different levels of $\mathrm{NaCl}(0,50,100$, and $200 \mathrm{mM}$ ) under the same culture conditions as above. After 14 days of salt stress, the genotoxic effect was determined using the techniques described below. Thirtyday-old seedlings of the three tested cultivars cultured on MS medium are shown in Fig. 1.

\section{Isolation of nuclei}

Individual leaf explants were removed from the seedlings and maintained in a petri dish on ice in Sörensen buffer [50 $\mathrm{mM}$ sodium phosphate, $\mathrm{pH} 6.8,0.1 \mathrm{mM}$ ethylenediamine tetraacetic acid (EDTA) and $0.5 \%$ dimethyl sulfoxide (DMSO)]. The leaf tissue explant was gently sliced with a razor blade and the obtained material was repeatedly immersed in the cold Sörensen buffer. The suspension including released nuclei was filtered through $30 \mu \mathrm{m}$ disposable filter (Partec, Münster, Germany) to exclude most of the cell debris and then centrifuged at $550 \times \mathrm{g}$ for 5 $\min$ at $4^{\circ} \mathrm{C}$.

\section{Genotoxicity assay}

Leaves were placed in a small Petri dish with $200 \mathrm{~mL}$ of cold $400 \mathrm{mM}$ Tris-HCl buffer, $\mathrm{pH} 7.5$ (on ice). Using a razor blade, the leaves were gently sliced into a "fringe" to liberate nuclei into the buffer, as viewed under yellow light. This method of nucleus isolation was confirmed as optimal for obtaining low values of DNA damage in the control cells. Slides were coated with $1 \%$ normal melting point (NMP) agarose, dried, wrapped with a mixture of $55 \mu \mathrm{L}$ of nuclear suspension and $55 \mu \mathrm{L}$ of LMP agarose (low melting point (LMP) (1\% prepared with phosphate-buffered saline) at $40^{\circ} \mathrm{C}$, and cover slipped. The slide was placed on ice for at least $5 \mathrm{~min}$, and then the coverslip was removed. A $110 \mu \mathrm{L}$ 

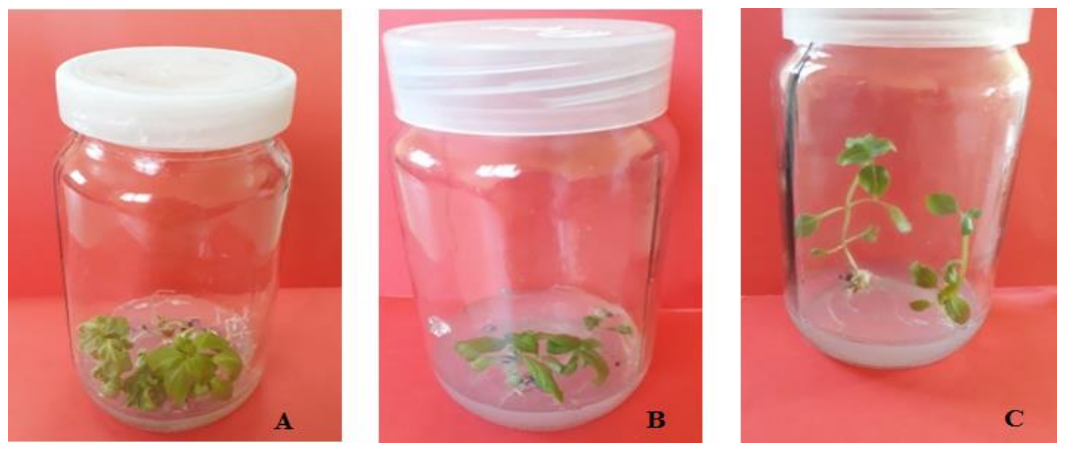

Fig. 1: In vitro culture of three basil cultivars on free hormone MS medium after 30 days. (A) $O$. basilicum cv. Gigante, (B) $O$ basilicum cv. Gralissimum and (C) O basilicum cv. Verde

Table 1: Primers used for PCR simplification

\begin{tabular}{ll}
\hline Gene & Forward primer $5^{\prime}-3^{\prime}$ \\
Actin & GTTCTCAGTGGTGGCTCAACTATGT \\
FPPS & GGCACTAGAACTTTCAAACGAA \\
DXR & GTTGCGGTAAGAAATGAGTCAT \\
HK & GATATTGTGGGAGAATTGACCAG \\
GPPS & AGTATTGGCAGGAGATCTTCTAC \\
LS & CTTTCGACTTCTCAGACAACAAG
\end{tabular}

volume of LMP agarose $(0.5 \%)$ was then carefully placed on the slide and the coverslip was placed again. After 5 min on ice, the coverslip was removed slowly. Single Cell Gel Electrophoresis (SCGE) slides with plant or cell nuclei were exposed to the mutagen solutions for $2 \mathrm{~h}$ at $26^{\circ} \mathrm{C}$, followed by washing three times for $5 \mathrm{~min}$ in cold distilled water. The slides with plant cell nuclei were placed in a horizontal gel electrophoresis tank containing freshly prepared cold electrophoresis buffer $(300 \mathrm{mM} \mathrm{NaOH}, 1 \mathrm{mM}$ EDTA, $\mathrm{pH}>13$ ) and incubated for $15 \mathrm{~min}$. The electrophoresis was then run at $16 \mathrm{~V}, 300 \mathrm{~mA}$ for $30 \min 16 \mathrm{~V}, 300 \mathrm{~mA}$ at $4^{\circ} \mathrm{C}$. These electrophoresis conditions were previously confirmed as ideal as they resulted in only low levels of DNA damage in control cells and gave linear responses for comets after chemical mutagen treatment of these cultivars in pilot studies. The gels were then neutralised by washing three times in $400 \mathrm{mM}$ Tris-HCl, $\mathrm{pH}$ 7.5, stained with ethidium bromide $(20 \mu \mathrm{g} / \mathrm{mL})$ for $5 \mathrm{~min}$, immersed in ice-cold distilled water and immediately analysed. For each slide, 50 randomLy selected cells were examined with a fluorescence microscope equipped with a $546 \mathrm{~nm}$ excitation filter, a 590 $\mathrm{nm}$ barrier filter and a computerised image analysis system (Komet Version 3.1 Kinetic Imaging, Liverpool, UK). The Tail moment (TM) and DNA (TD, \%) served as the parameters of DNA damage (Jolanta et al. 2006).

\section{RNA extraction and gene expression}

RNA extraction: Total RNA was extracted from $0.5 \mathrm{~g}$ samples of basil plant tissues (MacRae 2007) by adding 500 $\mu \mathrm{L}$ of Trizol reagent, grinding the sample thoroughly, adding $100 \mu \mathrm{L}$ chloroform, shaking well, and then

\author{
Genes of terpene biosynthesis pathway \\ House keeping \\ Farnesyl pyrophosphate synthase \\ Deoxy-D-xylulose 5- phosphate reductoisom \\ Hexokinase \\ Geranyl diphosphate synthase \\ Linalool synthase
}

centrifuging for $5 \mathrm{~min}$ at $13000 \mathrm{~g}$. The upper layer was carefully removed, $250 \mu \mathrm{L}$ isopropanol was added, and the mixture was shaken lightly to promote the formation of RNA strands. The tube was placed in a freezer at $-2^{\circ} \mathrm{C}$ for 30 min until the RNA had precipitated. The tube was centrifuged for $5 \mathrm{~min}$ at $13000 \mathrm{~g}$, the supernatant was removed, and the pellet was suspended in $500 \mu \mathrm{l}$ diethylpyrocarbonate (DEPC)-treated water: ethanol (25\%:75\%) and centrifuged for $5 \mathrm{~min}$. The supernatant was removed, the pellet was allowed to dry, and was then dissolved in $50 \mu \mathrm{L}$ DEPC water in a $55-60^{\circ} \mathrm{C}$ water bath for $15 \mathrm{~min}$. The quality of the isolated RNA was verified by agarose gel electrophoresis (1\% agarose in $1 \mathrm{X}$ TBE buffer). The extracted RNA was checked for purity on the $1 \%$ agarose gel by visualisation with a UV transilluminator (Biometra UV star 15).

First strand cDNA synthesis reaction: The cDNAs were synthesised from $2 \mu \mathrm{L}$ of total RNA in a final reaction volume of $20 \mu \mathrm{L}$ using a Revert First Strand cDNA synthesis kit (Thermoscientific, Lithuania) according to the manufacturers instructions. The cDNA protocol included the following steps: Oligo $(\mathrm{dT})_{18}$ primer (about $1 \mu \mathrm{L}$ ) was added to $2 \mu \mathrm{L}$ RNA, $4 \mu \mathrm{l} 5 \mathrm{X}$ reaction buffer, $1 \mu \mathrm{L}$ RiboLock RNase inhibitor $(20 \mu \mathrm{g} / \mu \mathrm{L}), 2 \mu \mathrm{L} 10 \mathrm{mM}$ dNTP Mix, $1 \mu \mathrm{L}$ Revert Aid RT ( $200 \mu \mathrm{g} / \mu \mathrm{L}), 9 \mu \mathrm{L}$ nuclease-free water, and the final volume was adjusted to $20 \mu \mathrm{L}$ by addition of DEPC-treated water, mixed, and incubated for $60 \mathrm{~min}$ at $42^{\circ} \mathrm{C}$. The reaction was terminated by heating at $70^{\circ} \mathrm{C}$ for 5 min and then chilling on ice for at least 3-5 mins.

Polymerase chain reaction: Reverse transcription was performed with High Capacity Access RT-PCR System (Promega) using aliquots of total RNA extracted following 
the manufacturer's instructions. The sequences of the selected primers for the secondary product genes (LS, HK, FPPS, GPPS and DXR) were obtained from previous studies (Table 1). The Master PCR reaction mix contained $2 \mu \mathrm{L}$ cDNA, $0.6 \mu \mathrm{L}$ primer, $4 \mu \mathrm{L}$ PCR Master mix, in a volume adjusted to $20 \mu \mathrm{L}$ by adding $12.8 \mu \mathrm{L}$ distilled water; a negative control was also prepared. Semi-quantitative RTPCR reactions were performed using a PXE 0.5 thermocycler (Thermo Scientific) with the following cycling program: Stage $1,94^{\circ} \mathrm{C}$ : $2-4 \mathrm{~min}$; Stage 2 (40 cycles), $94^{\circ} \mathrm{C}$ : $30 \mathrm{~S} ; 61.1^{\circ} \mathrm{C}: 1 \mathrm{~min} ; 68^{\circ} \mathrm{C}: 2 \mathrm{~min}$; Stage 3: $68^{\circ} \mathrm{C}$ : $7 \mathrm{~min}$; Stage 4 : hold at $4^{\circ} \mathrm{C}$. The sqRT-PCR products were visualised by conventional agarose gel electrophoresis. The generated bands were quantified using GelPro32 (version 4.03).

Agarose gel electrophoresis: The PCR products were examined by electrophoresis, as described previously, using $1.5 \%$ agarose gel at $100 \mathrm{~V}$ for $90 \mathrm{~min}$. The samples were detected using UV trans-elements and imaged. A DNA ladder with a molecular size range of 100-1500 bp was used to determine the size of the reaction products. The results were analysed using a GEL pro computer program (Version32).

\section{Statistical analysis}

Each data element reflects the mean of three biological samples, with three replicates for each plant sample. Statistical analysis for all experiments was performed using Graph Pad Prism 8 (Graph Pad Software, La Jolla, CA, USA). One-way analysis of variance (ANOVA) was used to analyse the data. Values of $p<0.05$ were considered statistically significant. The results were expressed as mean \pm standard deviation (SD).

\section{Results}

\section{DNA fragmentation dependent test (Comet assay)}

Nuclear DNA damage was assessed in each basil cultivar cultured on MS medium supplemented with $0.0,50,100$ or $200 \mathrm{mM} \mathrm{NaCl}$. The important comet assay parameters measured in this study to evaluate DNA damage were Tail moment, DNA tail (\%) and tail length. Fig. 2 shows greater dose-scored DNA damage in $O$. basilicum Gigante plants exposed to $50 \mathrm{mM} \mathrm{NaCl}$ than in untreated control plants. Exposure to $200 \mathrm{mM} \mathrm{NaCl}$ resulted in DNA damage scores of $2.05 \%$ for DNA tail (\%); this was a highly significant increment compared with the untreated plants (Fig. 2B). The score was $1.39 \%$, again a significant increment over the control, when plants were treated with $100 \mathrm{mM} \mathrm{NaCl}$. The levels of 100 and $200 \mathrm{mM} \mathrm{NaCl}$ gave highly significant damage, as determined by tail moment measurements of 2.1 and 4.4 units, respectively (Fig. 2C). Damage expressed by tail length in DNA was relatively higher and reached 1.13, 1.52 and $2.16 \mu \mathrm{m}$ in $O$. basilicum Gigante plants cultured on
MS medium with 50, 100 and $200 \mathrm{mM} \mathrm{NaCl}$, respectively, whereas the control plants showed no damage based on the tail length in DNA (Fig. 2D). Similar results were recorded for the Gralissimum and Verde varieties using similar comet assay parameters and scoring against control plants Damage appeared to increase with increases in salt stress above 50 $\mathrm{mM} \mathrm{NaCl}$ (Fig. 2, 3, 4B, C and D) in all samples, as evident by significant increases in DNA tail (\%), tail moment and tail length.

\section{Gene expression analysis}

Exposure to $\mathrm{NaCl}$ stress affected the expression of FPPS, DXR, HK, GPPS and LS genes in in vitro cultures of all three basil cultivars and confirmed the correlation between $\mathrm{NaCl}$ stress of and changes in transcription of terpene biosynthesis genes in the three cultivars. The genes responsible for production of the expected precursors in the pathway were also monitored by semi-quantitative PCR using five primers for genes in the terpene biosynthesis pathway and recording the changes occurring in the basil cultivars treated with various levels of $\mathrm{NaCl}$ (Fig. 2, 3, 4F$\mathrm{G})$. The actin gene was used as a housekeeping gene. All three cultivars showed accumulation of LS and HK synthase transcripts in response to salinity stress when compared with the sesquiterpene synthase enzymes FPPS, 1-deoxy-D-xylulose-5-phosphate reductoisomerase (DXR) and GPPS.

The expression profiles of FPPS, GPPS and DXR indicated a significantly lower induction of transcript accumulation by salinity in the Gigante variety (Fig. 2). The expression patterns indicated a rapid response and sharp increase in the LS transcript amount (2.79) in the Gigante plants cultured on MS medium supplemented with $200 \mathrm{mM}$ $\mathrm{NaCl}$ compared to control plants (0.06). Higher LS expression (1.84 and 1.54) was also observed in plants exposed to salinity stress $(50 \mathrm{mM}$ and $100 \mathrm{mM} \mathrm{NaCl}$, respectively). The accumulation of the HK transcript also showed a significant increase to 3.17 in plants exposed to $200 \mathrm{mM} \mathrm{NaCl}$ versus the control plants (1.57). Notably, the HK transcript amounts were similar to the control levels (1.6) in plants exposed to $100 \mathrm{mM} \mathrm{NaCl}$. The $\mathrm{HK}$ transcripts in plants cultured on $50 \mathrm{mM} \mathrm{NaCl}$ showed no clear trend and no significant difference in amount (2.1) compared to the unstressed control plants (Fig. 2).

The effect of different levels of salinity stress on the transcription of selected genes involved in terpene biosynthesis transcription was also examined in the Gralissimum variety (Fig. 3). The HK transcript content was similar to control levels in plants exposed to $50 \mathrm{mM} \mathrm{NaCl}$ (1.4), whereas plants cultured on $200 \mathrm{mM} \mathrm{NaCl}$ had $\mathrm{HK}$ levels of 2.8. The amount of LS transcript showed a gradual decrease in response to increases in salinity stress (Fig. 3).

The FPPS, DXR and GPPS transcript contents were lowest in the Verde variety and were minimal under salinity conditions. O. basilicum Verde plants treated with 0.0, 50, 


\section{O. basilicum cv. Gigante}

A
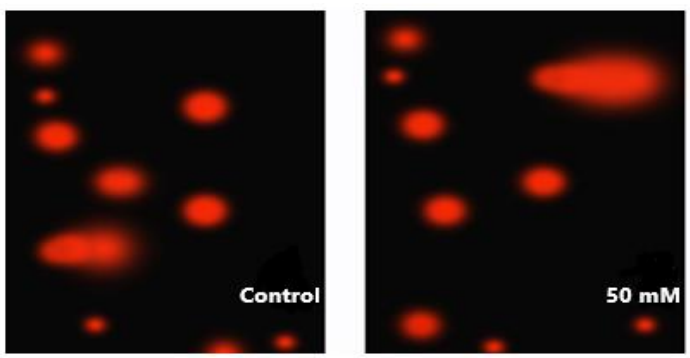

B

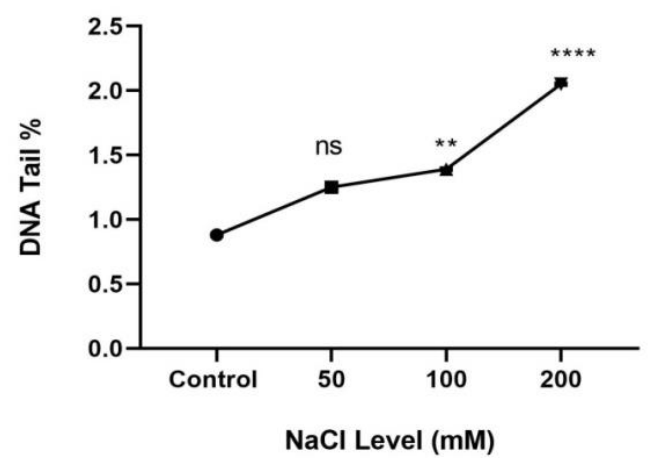

D

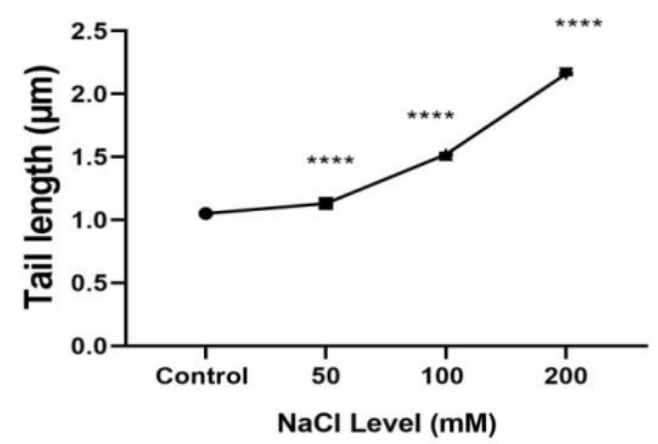

$\mathbf{F}$

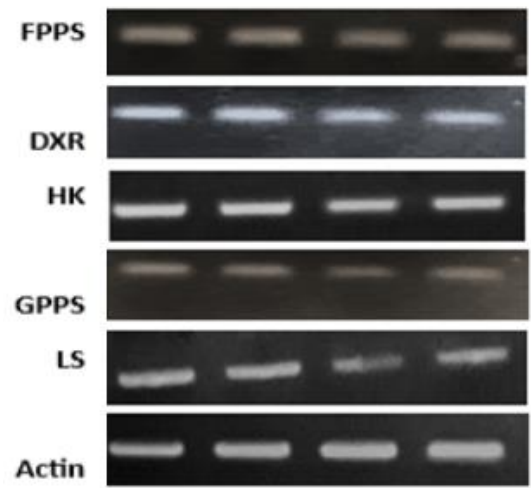

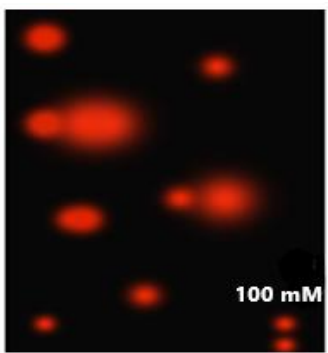

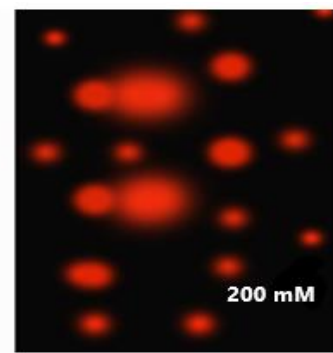

C

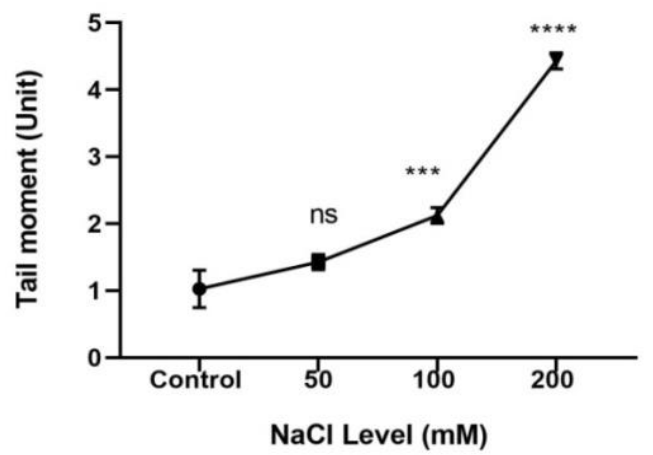

E

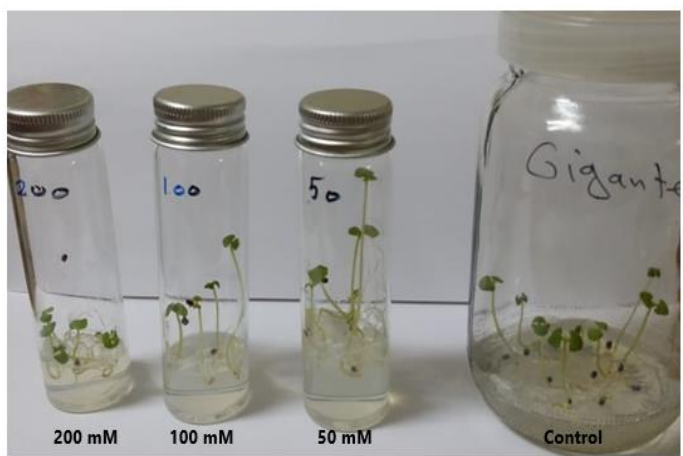

G

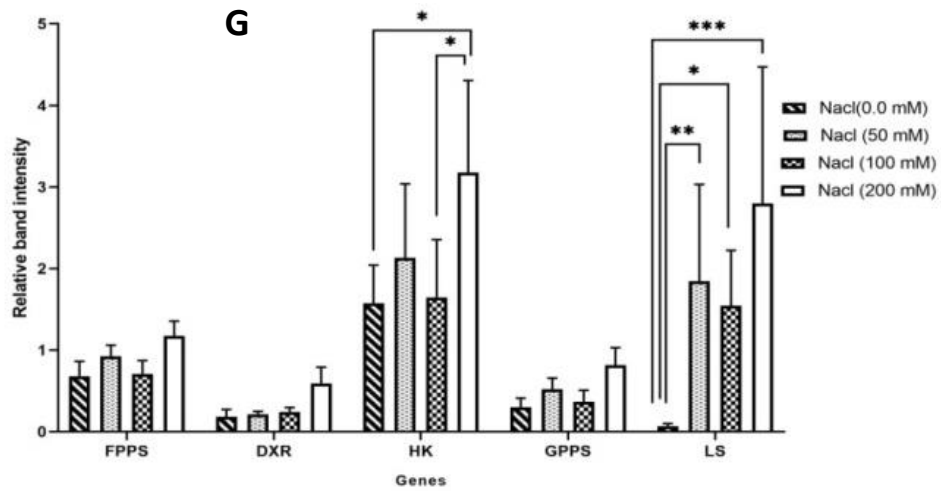

Fig. 2: Genotoxicity of salinity at four levels $(0.0,50,100$ and $200 \mathrm{mM} \mathrm{NaCl})$ on Gigante cultivar of $O$. basilicum grown on MS medium. (A) Comet assay: Photomicrographs of ethedium bromide -stained DNA from protoplasts of $O$. basilicum Gigante exposed to four levels of $\mathrm{NaCl}$ stress, (B) DNA Tail (\%), (c) Tail moment (Unit), (D) Tail length $(\mu \mathrm{m})$, (E) In vitro shoot cultures of $O$. basilicum Gigante exposed to MS medium supplemented with $(0.0,50,100$ and $200 \mathrm{mM} \mathrm{NaCl}),(\mathrm{F})$ Agarose gel electrophoresis stained by ethidium bromide results showing the expression of FPPS, DXR, HK, GPPS and LS genes amplified in O. basilicum Gigante plant cultures exposed to salinity stress determined by semi-quantitative-PCR. Lane1: Control, lane 2: $50 \mathrm{mM}$, lane 3: $100 \mathrm{mM}$ or, lane 4: $200 \mathrm{mM}$ Nacl (G) Terpenes biosynthesis genes and their inhibitors / actin expression ratio 


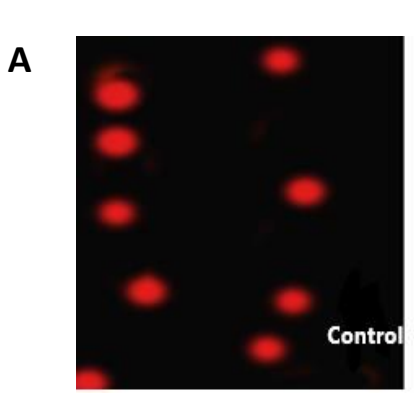

\section{O. basilicum cv. Gralissimum}

B

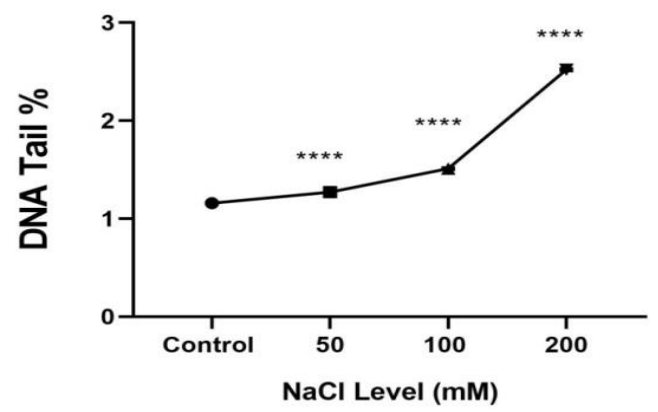

D

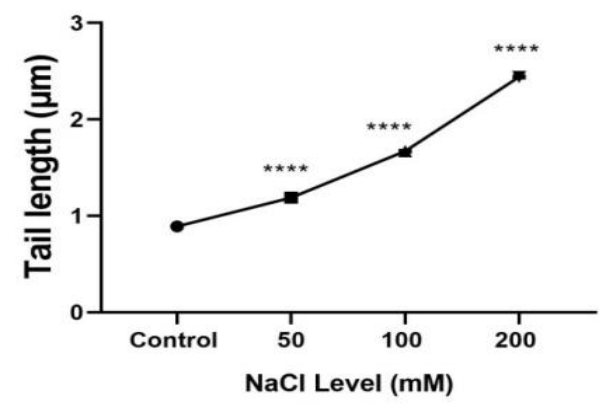

$\mathbf{F}$

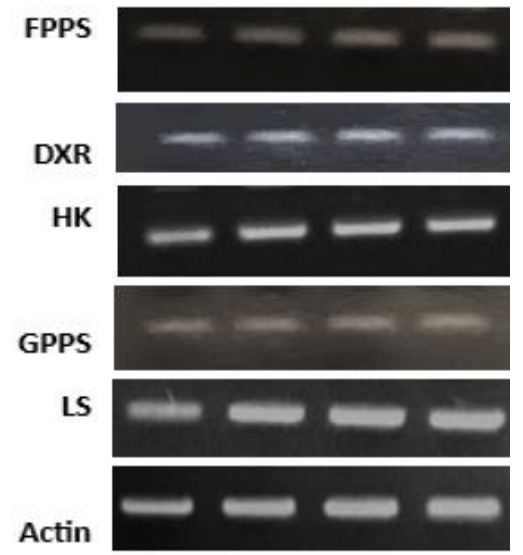

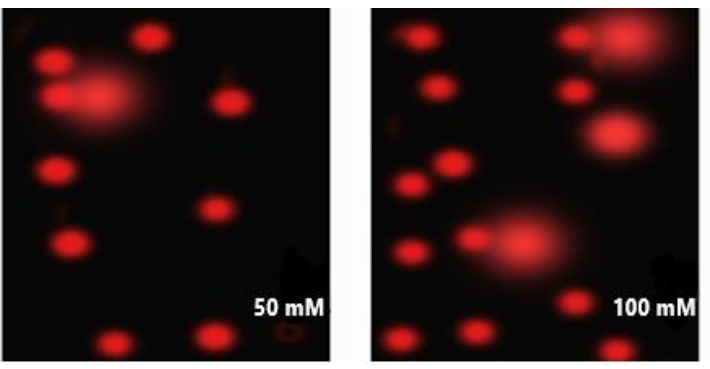

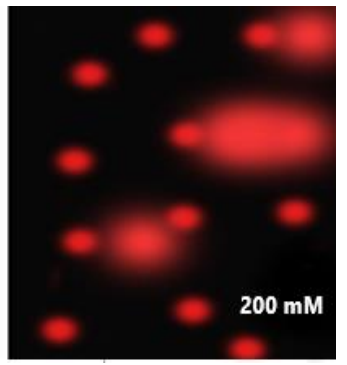

C

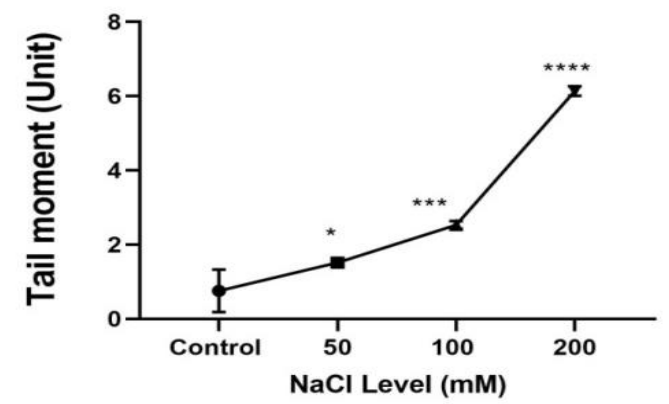

E

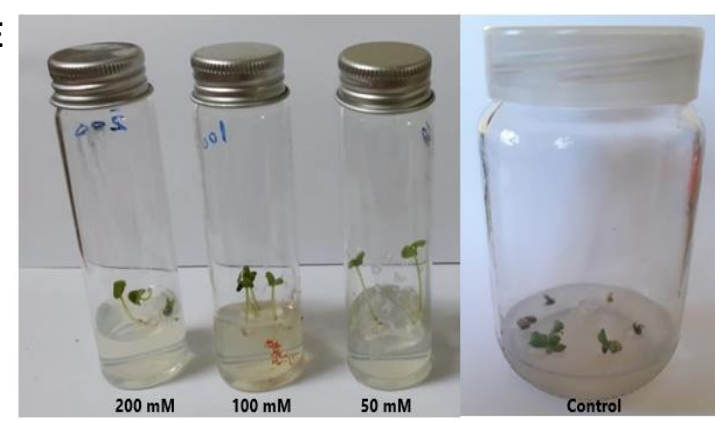

G

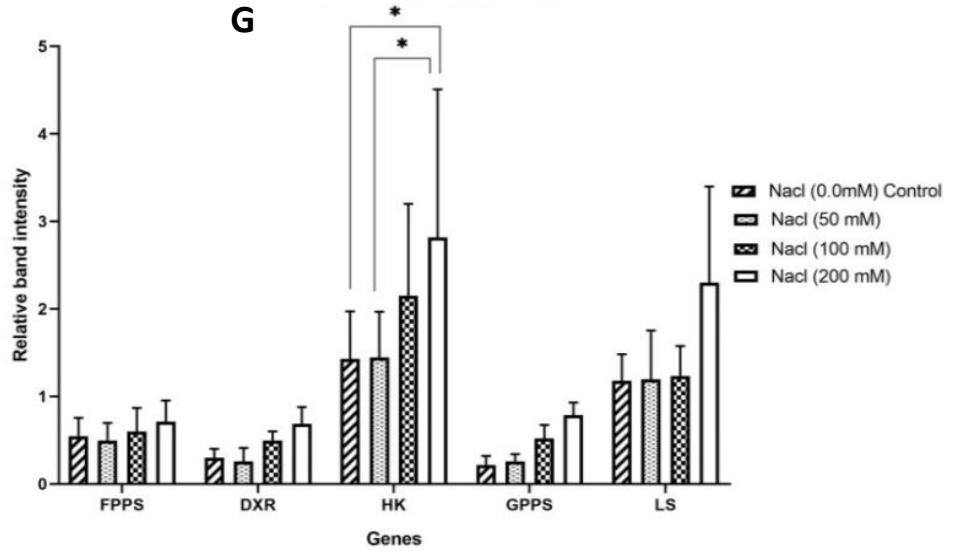

Fig. 3: Genotoxicity of salinity at four levels $(0.0,50,100$ and $200 \mathrm{mM} \mathrm{NaCl})$ on Gralissimum cultivar of $O$. basilicum grown on $\mathrm{MS}$ medium. (A) Comet assay: Photomicrographs of ethedium bromide -stained DNA from protoplasts of $O$. basilicum Gralissimum exposed to four levels of $\mathrm{NaCl}$ stress, (B) DNA Tail \%, (c) Tail moment (Unit), (D) Tail length ( $\mu \mathrm{m})$, (E) In vitro shoot cultures of $O$. basilicum Gralissimum exposed to MS medium supplemented with $(0.0,50,100$ and $200 \mathrm{mM} \mathrm{NaCl})$, (F) Agarose gel electrophoresis stained by ethidium bromide results showing the expression of FPPS, DXR, HK, GPPS and LS genes amplified in $O$. basilicum Gralissimum plant cultures exposed to salinity stress determined by semi-quantitative-PCR. Lane1: Control, lane 2: $50 \mathrm{mM}$, lane 3: $100 \mathrm{mM}$ or, lane 4: 200 $\mathrm{mM} \mathrm{Nacl}(\mathrm{G})$ Terpenes biosynthesis genes and their inhibitors/ Actin expression ratio 


\section{O. basilicum cv. Verde}

A
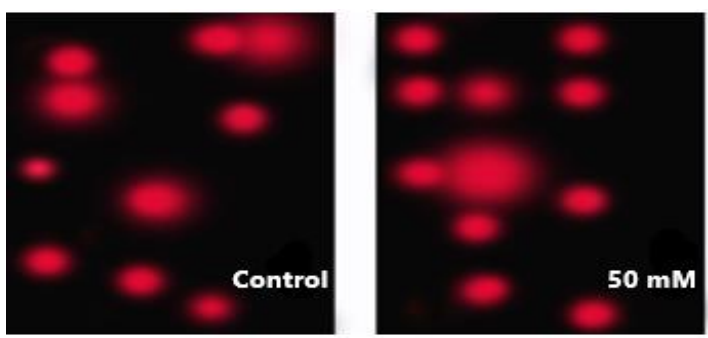

B

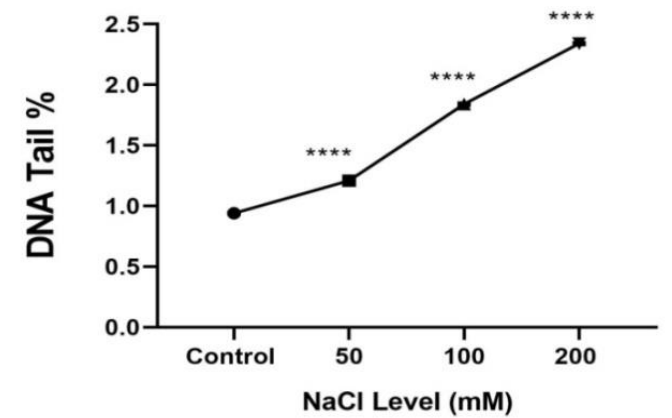

D

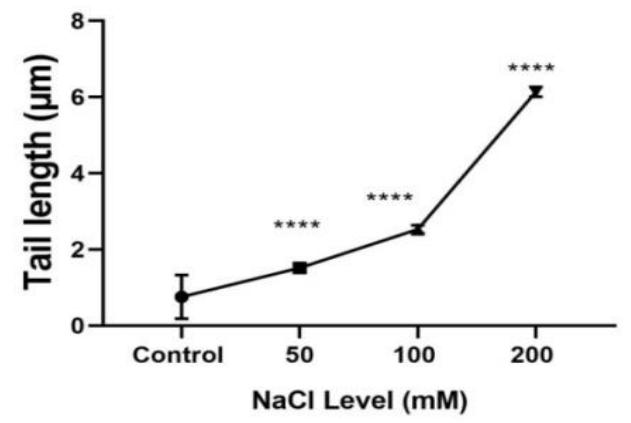

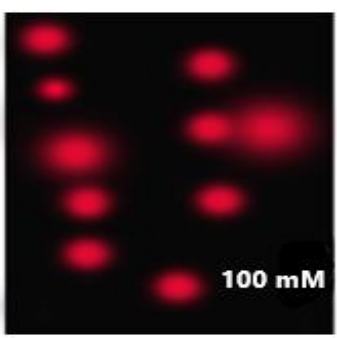

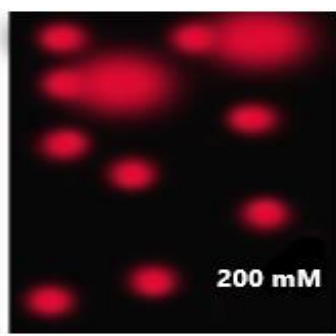

C

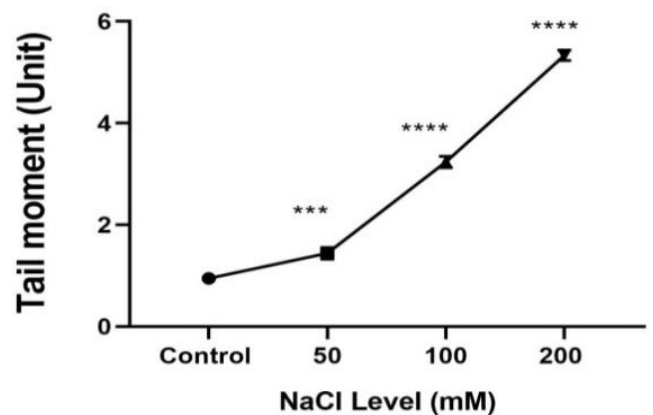

E

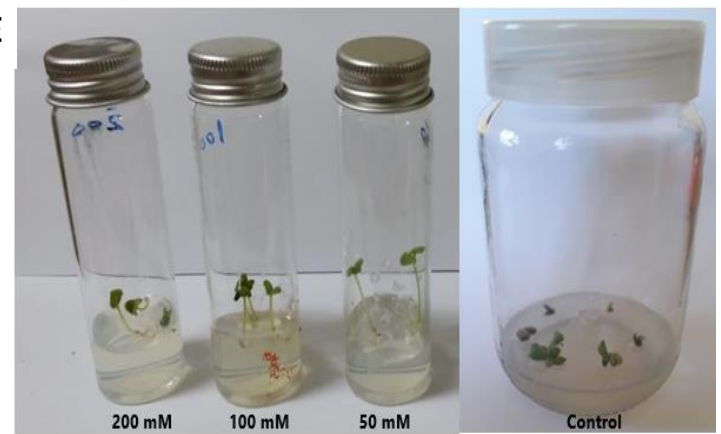

G

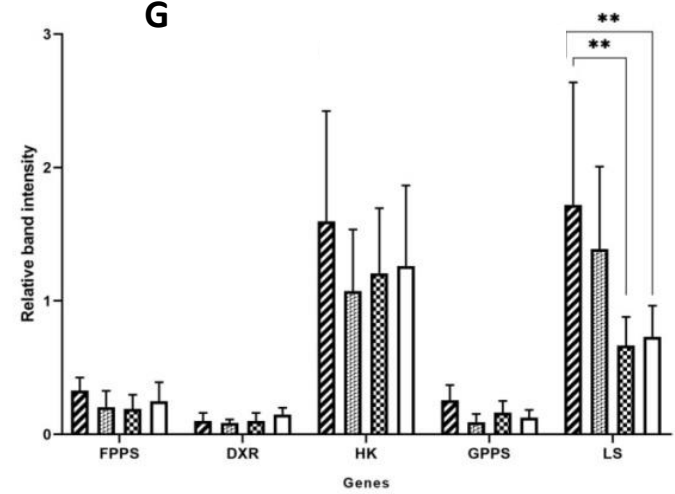

西 $\mathrm{Nacl}(0.0 \mathrm{mM})$

macl $(100 \mathrm{mM})$

口 $\operatorname{Nacl}(200 \mathrm{mM})$

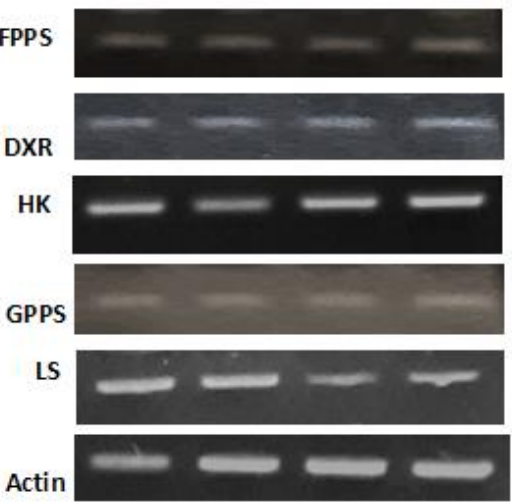

Fig. 4: Genotoxicity of salinity at four levels $(0.0,50,100$ and $200 \mathrm{mM} \mathrm{NaCl})$ on Verde cultivar of $O$. basilicum grown on MS medium. (A) Comet assay: Photomicrographs of ethedium bromide -stained DNA from protoplasts of $O$. basilicum Verde exposed to four levels of $\mathrm{NaCl}$ stress, (B) DNA Tail \%, (c) Tail moment (Unit), (D) Tail length $(\mu \mathrm{m})$, (E) In vitro shoot cultures of O. basilicum Verde exposed to MS medium supplemented with $(0.0,50,100$ and $200 \mathrm{mM} \mathrm{NaCl}),(\mathrm{F})$ Agarose gel electrophoresis stained by ethidium bromide results showing the expression of FPPS, DXR, HK, GPPS and LS genes amplified in $O$. basilicum Verde plant cultures exposed to salinity stress determined by semi-quantitative-PCR. Lane1: Control, lane 2: $50 \mathrm{mM}$, lane 3: $100 \mathrm{mM}$ or, lane 4: $200 \mathrm{mM}$ Nacl (G) Terpenes biosynthesis genes and their inhibitors / Actin expression ratio 
100 and $200 \mathrm{mM} \mathrm{NaCl}$ showed high amounts and specific activity of LS, the key enzyme in the linalool synthase pathway (Fig. 4), and the LS transcript levels were higher (1.7) in the control plants than in the plants exposed to salinity stress of 100 and $200 \mathrm{mM} \mathrm{NaCl}$. A relative band intensity of 1.3 was recorded when Verde plants were cultured in $50 \mathrm{mM} \mathrm{NaCl}$, but this value was not significantly different from the value obtained for the untreated control. Therefore, $\mathrm{NaCl}$ stress had an effect on the expression of genes involved in hexokinase biosynthesis the Verde plants; however, this increase in transcription in response to the different salinity treatments was not statistically significant. The expression patterns for the FPPS, DXR and GPPS genes under salinity stress are shown in Fig. 4 and indicated a dramatic decrease in transcription in response to salinity.

\section{Discussion}

The most accurate parameters reflecting salinity-induced DNA damage were the DNA tail percentage, which was expressed as the total intensity of the tailing, and the total intensity of the comet, which does not depend on the length of the tail. Boyko et al. (2010) and Nikolova et al. (2013) explained that DNA damage caused by treating plants with $\mathrm{NaCl}$ is considered a genotoxic effect that leads to altered transgene ratios and somatic changes in recombination rates, due primarily to exposure to $\mathrm{Cl}^{-}$ions. Previous studies have highlighted the increases in oxidative stress as a cause of $\mathrm{Al}$ genotoxicity. Investigation of the mechanisms of $\mathrm{Al}$ genotoxicity by comet assays revealed a role for cell wallbound NADHPX in the Al-mediated oxidative burst (Achary et al. 2012). The mechanics of signal transmission involved $\mathrm{Ca}^{2+}$ ions (Achary et al. 2013) and MAP kinases (Panda and Achary 2014), leading to Al-caused cell death and DNA damage. Monteiro et al. (2012) clarified that $\mathrm{Cd}$ toxicity induces DNA repair mechanisms and these create adducts of Cd-DNA that result in protein cross-links and long DNA fragments and/or it triggers a failure of the DNA repair mechanisms.

Two studies on $A$. cepa investigated the role of oxidative stress role in $\mathrm{Pb}$-induced genotoxicity and found that the cell cycle has an important role in DNA damage (Jiang et al. 2014; Kaur et al. 2014). It was showed that the effects of $\mathrm{NaCl}$ on genome stability were due to $\mathrm{Cl}^{-}$ions, whereas $\mathrm{Na}^{+}$ions had no effect on the recombination rates (RR), as media supplemented with $\mathrm{Cl}^{-}$ions but not $\mathrm{Na}^{+}$ showed the same increase in the frequency of genomic rearrangements (Smoleń et al. 2020). The mechanism involved in this $\mathrm{Cl}^{-}$ion effect on genome equilibrium is still not specified. The toxic levels of $\mathrm{Na}^{+}$lead to marked defects in ion homeostasis in the plant cytoplasm that ultimately result in a $\mathrm{K}^{+}$deficiency (Hasegawa et al. 2000), but the genotoxicity of $\mathrm{NaCl}$ stress depends on $\mathrm{Cl}^{-}$.

The imposition of $\mathrm{NaCl}$ salinity stress on the three basil cultivars caused adverse effects that were mainly observed in the content of plant secondary products. In fact, abiotic stresses like $\mathrm{NaCl}$ salt stress slow down plant growth, a response that is considered evidence of plant adaptation and vitality under salinity pressure (Sabir et al. 2012). Our findings illustrated that exposure to salt stress triggered a high accumulation of terpenoids, in spite of the cell damage and restrictions in plant growth, by maintenance of clear sources of metabolite precursors. Coordination of the terpenoid pathway-specific genes was the major reason for terpenoid accumulation. Sangwan et al. (2011) mentioned that the phytochemicals synthesised and included in glandular trichomes are very important for the plant defence in cases of exposure to biotic and abiotic stresses.

The transcription activity of FPPS, DXR and GPPS genes, as well as of LS (which is expressed strongly in $O$. basilicum Gigante and Verde when cultured on media supplemented with 50, 100 and $200 \mathrm{mM} \mathrm{NaCl}$ ), was enhanced, as shown by semi-quantitative RT-PCR analysis (Table 1). Our data agreed with those of Lane et al. (2010), who reported that the major component of Lavandula angustifolia essential oil is linalool and that LS expression is responsible for the accumulation of linalool in lavender flowers. This is not unexpected, as a terpenoid synthase enzyme can convert a single molecule into various products (Toll et al. 2005; Degenhardt et al. 2009).

The HK gene is the second enzyme pathway gene that was highly expressed in the Gigante and Gralissimum cultivars in response to different salinity levels. As reported by Graham et al. (1994), HK is not only valuable for expression of sugar-inducible and sugar-repressible genes in higher plants but it has also been proposed to serve as a sensor for sugar suppression of genes involved in the glyoxylate cycle in higher plants. HK is a known enzyme of glycolysis that accelerates the ATP-dependent conversion of hexoses to hexose-6-phosphates, and it has been proposed as a glucose sensor in higher and lower eukaryotes (Jyan et al. 1997). In the current study, the band intensity of the RNA transcripts of selected genes (FPPS, DXR and GPPS) appeared to be lower when compared to the LS and HK gene transcripts in all three cultivars at all levels of salinity. Xiao et al. (2015) explained that, among the MEP pathway genes identified in Salvia miltiorrhiza, DXS was the principal ratelimiting reaction in the pathway. Kai et al. (2011) concluded that expression of SmDXS2 was related to the accumulation of phenanthrene secondary products like tanshinones.

FPPS is considered a key enzyme in isoprenoid biosynthesis reactions as it provides the sesquiterpene precursors for different essential metabolites, including ubiquinones, dolichols, sterols and carotenoids, as well as substrates for geranyl geranylation and farnesylation of proteins. It catalyses sequential head-to-tail condensation of two molecules; dimethylallyl diphosphate and isopentenyl diphosphate. FPPS is usually a homodimer of subunits, and the FPPS-encoding genes in Arabidopsis thaliana are controlled at both the expression and transcription levels (Szkopińska and Plochocka 2005). One possibility is that a mitochondrial isoform is transcribed and translated into a 
protein or peptide without a signal sequence (Cunillera et al. 1997).

GPPS is a key enzyme in monoterpene biosynthesis and is localised in plastids (Tholl et al. 2004), the site of synthesis of most monoterpenes from dimethylallyl diphosphate and isopentenyl diphosphate. The heterodimeric form of GPPS consists of a non-catalytic small subunit (GPPS-SSU) that interacts with the large GPPS catalytic subunit and determines the product specificity (Michael et al. 2013).

\section{Conclusion}

The comet assay was an appropriate method for determining the DNA damage promoted by exposure of basil cultivars to known doses of a genotoxin, which was $\mathrm{NaCl}(200 \mathrm{mM})$ in the present study. Semi-quantitative RT-PCR of the LS and HK transcripts confirmed that these genes maintained comparatively stable expression under salinity stress in cell cultures from all three basil cultivars. The results highlight the potential of post-transcriptional regulation of LS and HK, which are abundantly expressed in plant cells under salinity stress.

\section{Acknowledgment}

Taif University Researchers Supporting Project number (TURSP-2020/38), Taif University, Taif, Saudi Arabia is highly appreciated. Author appreciates the help of Dr. Hadeer Darwesh for tissue culture and genotoxicity assays and arrangement.

\section{Conflict of interest}

I declare no conflict of interest of any sort

\section{Data Availability}

All data relevant to this research are available with the author

\section{Ethics Approval}

No applicable

\section{References}

Achary VM, NL Parinandi, BB Panda (2012). Aluminum induces oxidative burst, cell wall NADH peroxidase activity, and DNA damages in root cells of Allium cepa L. Environ Mol Mutagen 53:550-560

Achary VM, NL Parinandi, BB Panda (2013). Calcium channel blockers protect against aluminium - induced DNA damages and blockadaptive response to genotoxic stress in plant cells. Mutat Res Genet Toxicol Environ Mutagen 751:130-138

Ashour M, M Wink, J Gershenzon (2010). Biochemistry of terpenoids: Monoterpenes, sesquiterpenes and diterpenes. Annu Plant Rev 40:258-303

Boyko A, A Golubov, A Bilichak, I Kovalchuk (2010). Chlorine ions but not sodium ions alter genome stability of Arabidopsis thaliana. Plant Cell Physiol 51:1066-1078
Cunillera N, A Boronat, A Ferrer (1997). The Arabidopsis thaliana FPS1 gene generates a novel mRNA that encodes a mitochondrial farnesyldiphosphate synthase isoform. J Biol Chem 272:15381-15388

Davenport SB, SM Gallego, MP Benavides, ML Tomaro (2003). Behaviour of antioxidant defense system in the adaptive response to salt stress in Helianthus annuus L. cells. Plant Growth Regul 40:81-88

Degenhardt J, TG Köllner, J Gershenzon (2009). Monoterpene and sesquiterpene synthases and the origin of terpene skeletal diversity in plants. Phytochemistry 70:1621-1637

Gershenzon J, W Kreis (1999). Biochemistry of terpenoids: Monoterpenes, sesquiterpenes, diterpenes, sterols, cardiac glycosides and steroid saponins. In: Biochemistry of Plant Secondary Metabolism, pp: 222 299. Wink M (ed.). CRC Press, Boca Raton, Florida, USA

Ghosh M, S Bhadra, A Adegoke, M Bandyopadhyay, A Mukherjee (2015). MWCNT uptake in Allium cepa root cells induces cytotoxic and genotoxic responses and results in DNA hyper-methylation. Mutat Res Genet Toxicol Environ Mutagen 774:49-58

Gichner T, I Znidar, E Wagner, M Plewa (2009). The use of higher plants in the Comet Assay, Chapter 4. In: The Comet Assay in Toxicology, pp:98-119. Dhawan A, D Anderson (eds.). Royal Society of Chemistry, London

Graham IA, KJ Denby, CJ Leaver (1994). Carbon catabolite repression regulates glyoxylate cycle gene expression in cucumber. Plant Cell 6:761-772

Gu R, Q Liu, D Pei, X Jiang (2004). Understanding saline and osmotic tolerance of Populus euphratica suspended cells. Plant Cell Tiss Org Cult 78:261-265

Hasegawa PM, RA Bressan, JK Zhu, HJ Bohnert (2000). Plant cellular and molecular responses to high salinity. Annu Rev Plant Physiol Plant Mol Biol 51:463-499

Hassanpouraghdam MB, GR Gohari, SJ Tabatabaei (2010). Inflorescence and leaves essential oil composition of hydroponically grown Ocimum basilicum L. J Serb Chem Soc 75:1361-1368

Jiang Z, R Qin, HZ Zhang, J Zou, Q Shi, J Wang, W Jiang, D Liu (2014). Determination of $\mathrm{Pb}$ genotoxic effects in Allium cepa root cells by fluorescent probe, microtubular immunofluorescence and comet assay. Plant Soil 383:357-372

Jolanta J, G Agnieszka, M Jolanta (2006). DNA damage induced by mutagens in plant and human cell nuclei in acellular comet assay. Folia Histochem Cyto 44:127-131

Jyan CJ, L Patricia, Z Li, S Jen (1997). Hexokinase as a sugar sensor in higher plants. Plant Cell 9:5-19

Kai G, H Xu, C Zhou, P Liao, J Xiao, X Luo, L You, L Zhang (2011). Metabolic engineering tanshinone biosynthetic pathway in Salvia miltiorrhiza hairy root cultures. Metab Eng 13:319-327

Kaur G, HP Singh, DR Batish, RK Kohli (2014). Pb-inhibited mitotic activity in onion roots involved DNA damage and disruption of oxidative metabolism. Ecotoxicology 23:1292-1304

Labra M, M Miele, B Ledda, F Grassi, M Mazzei, F Sala (2004). Morphological characterization, essential oil composition and DNA genotyping of Ocimum basilicum L. cultivars. Plant Sci 167:725733

Lane A, A Boecklemann, G Woronuk, L Sarker, S Mahmoud (2010). A genomics resource for investigating regulation of essential oil production in Lavandula angustifolia. Planta 231:835-845

MacRae E (2007). Extraction of plant RNA. Meth Mol Biol 353:15-24

Michael G, O Irina, TH Thuong, DR Rachel, GF Mario, S Yaron, L Efraim, P Eran, D Natalia (2013). Cytosolic monoterpene biosynthesis is supported by plastid-generated geranyl diphosphate substrate in transgenic tomato fruits. Plant J 75:351-363

Monteiro C, C Santos, S Pinho, H Oliveira, T Pedrosa, C Dias (2012) Cadmium-induced cyto- and genotoxicity are organ-dependent in lettuce. Chem Res Toxicol 25:1423-1434

Moteki H, H Hibasami, Y Yamada, H Katsuzaki, K Imai, T Komiya, R Oncol (2002). Specific induction of apoptosis by 1,8-cineole in two human leukemia cell lines, but not a in human stomach cancer cell line. Oncol Rep 9:757-760

Murashige T, F Skoog (1962). A revised medium for rapid growth and bioassays with tobacco tissue cultures. Physiol Plantarum 15:473497 
Nikolova I, M Georgieva, L Stoilov, Z Katerova, D Todorova (2013). Optimization of Neutral Comet Assay for studying DNA doublestrand breaks in pea and wheat. J BioSci Biotechnol 2:151-157

Omidbaig R (2005). Production and Processing of Medicinal Plants, vol. 2. Astane Quds Publications, Tehran, Iran

Panda BB, VM Achary (2014). Mitogen-activated protein kinase signal transduction and DNA repair network are involved in aluminiuminduced DNA damage and adaptive response in root cells of Allium cepa L. Front Plant Sci 5; Article 256

Rodriguez CM, A Boronat (2002) Elucidation of the methylerythritol phosphate pathway for isoprenoid biosynthesis in bacteria and plastids. A metabolic milestone achieved through genomics. Plant Physiol 130:1079-1089

Sabir F, RS Sangwan, R Kumar, NS Sangwan (2012). Salt stress-induced responses in growth and metabolism in callus cultures and differentiating in vitro shoots of Indian ginseng (Withania somnifera Dunal). J Plant Growth Regul 10:344-356

Saira K, UZ Zafar, RA Habib, K Rehana (2014). Physiological and biochemical basis of salt tolerance in Ocimum basilicum L. J Med Plants Stud 2:18-27

Sangwan NS, R Kumar, S Srivastava, A Kumar, A Gupta, RS Sangwan (2011). Recent developments on secondary metabolite biosynthesis in Artemisia annua L. J Plant Biol 37:1-24

Sonwa MM (2000). Isolation and structure elucidation of essential oil constituents: Comparative study of the oils of Cyperus alopecuroides, Cyperus papayrus and Cypreus rotundus. Ph.D thesis, University of Hamburg, Germany
Smoleń S, A Lukasiewicz, M Klimek-Chodacka, R Baranski (2020). Effect of soil salinity and foliar application of jasmonic acid on mineral balance of carrot plants tolerant and sensitive to salt stress. Agronomy 10: Article 659

Szkopińska A, D Plochocka (2005). Farnesyl diphosphate synthase; regulation of product specificity. Acta Biochim Polonica 52:4555

Tholl D, CM Kish, I Orlova, D Sherman, J Gershenzon, E Pichersky, N Dudareva (2004). Formation of monoterpenes in Antirrhinum majus and Clarkia breweri flowers involves heterodimeric geranyl diphosphate synthase. Plant Cell 16:977-992

Toll D, F Chen, J Petri, J Gershenzon, E Pichersky (2005). Two sesquiterpene synthases are responsible for the complex mixture of sesquiterpenes emitted from Arabidopsis flowers. Plant J 42:757771

Tomas G, M Merten, DA Stavreva, S Ingo (2000). Malic hydrazide induces genotoxic effects but no DNA damage detectable by the comet assay in tobacco and field beans. Mutagenesis 15:385389

Ventura L, A Giovannini, M Savio, M Donà, A Macovei, A Buttafava, D Carbonera, A Balestrazzi (2013). Single cell gel electrophoresis (Comet) assay with plants: Research on DNA repair and ecogenotoxicity testing. Chemosphere 6:1-18

Xiao HM, M Ying, FT Jin, LH Ya, CL Yu, JM Xiao, S Ye, HC Guang, XL Hui, XR Qi, G Juan, QH Lu (2015). The biosynthetic pathways of tanshinones and phenolic acids in Salvia miltiorrhiza. Molecules 20:16235-16254 